\begin{tabular}{|c|c|c|}
\hline$?$ & $\begin{array}{c}\text { Klinikal Sains } 7(2)(2019) \\
\text { JURNAL ANALIS KESEHATAN } \\
\text { KLINIKAL SAINS }\end{array}$ & KLNNKALSANS \\
\hline UNIVERSITAS & http://jurnal.univrab.ac.id/index.php/klinikal & 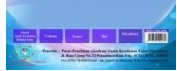 \\
\hline
\end{tabular}

\title{
BIOSORPSI ION LOGAM BERAT Pb(II) MENGGUNAKAN BIOSORBEN BATANG PISANG KEPOK (Musa Acuminata Balbisiana Colla)
}

\author{
Mega Elfia \\ D3 Refraksi Optisi, Akademi Refraksi Optisi YLPTK Padang \\ Jl. Berok Raya No.29 Jembatan Baru Siteba Padang \\ Telp (0751) 7054695 \\ Alamat e-mail mega_elfia@yahoo.com
}

\section{Info Artikel \\ Sejarah Artikel: \\ Diterima November 2019 \\ Disetujui Desember 2019 \\ Dipublikasikan Desember 2019}

Keywords:

Adsorbsi, Logam berat,

Konsentrasi ion logam,

ukuran partikel, Musa

acuminata balbisiana Colla

\begin{abstract}
Abstrak
Proses adsorpsi dengan menggunakan bahan-bahan biologis disebut sebagai biosorpsi dan adsorbennya dikenal sebagai biosorben. Biosorben yang digunakan dalam penelitian ini yakni limbah batang pisang kepok (Musa Acuminata Balbisiana Colla). Tujuan penelitian ini adalah untuk menghitung kapasistas penyerapan batang pisang kepok (Musa acuminata balbisiana Colla) terhadap ion logam $\mathrm{Pb}(\mathrm{II})$. Maka dari itu dilakukan penghitungan beberapa variable yakni konsentrasi ion logam $\mathrm{Pb}$ (II) dan ukuran partikel dari serbuk batang pisang kepok (Musa acuminata balbisiana Colla). Hasil penelitian didapatkan kondisi optimum penyerapan terhadap logam $\mathrm{Pb}$ (II). Konsentrasi larutan ion logam $\mathrm{Pb}(\mathrm{II}) 100 \mathrm{mg} / \mathrm{L}$ dan ukuran partikel $100 \mu \mathrm{m}$. Pada kondisi optimum tersebut diperoleh kapasitas penyerapan batang pisang kepok (Musa acuminata balbisiana Colla) terhadap ion logam Pb (II) adalah $1,9976 \mathrm{mg} / \mathrm{g}$. Berdasarkan hasil tersebut dapat disimpulkan bahwa batang pisang kepok (Musa acuminata balbisiana Colla) dapat digunakan sebagai bahan penyerap ion logam $\mathrm{Pb}$ (II).

Kata Kunci: Adsorbsi, Logam berat, Konsentrasi ion logam, ukuran partikel, Musa acuminata balbisiana Colla

Abstrac

The process of adsorption using biological materials is called biosorption and the adsorbent is known as biosorbent. Biosorbent used in this research was Kepok banana stem waste (Musa Acuminata Balbisiana Colla). The purpose of this study was to calculate the absorption capacity of Kepok banana stems (Musa acuminata balbisiana Colla) against $\mathrm{Pb}$ (II) metal ions. Therefore several variables were calculated, namely the concentration of $\mathrm{Pb}$ (II) metal ions and the particle size of the Kepok banana stem powder (Musa acuminata balbisiana Colla). The results obtained optimum conditions of absorption of $\mathrm{Pb}$ (II) metal. Concentration of $\mathrm{Pb}$ (II) metal ion solution is $100 \mathrm{mg} / \mathrm{L}$ and the particle size is $100 \mu \mathrm{m}$. In this optimum condition, the absorption capacity of Kepok banana stem (Musa acuminata balbisiana Colla) to the metal ion $\mathrm{Pb}$ (II) is $1.9976 \mathrm{mg} / \mathrm{g}$. Based on these results it can be concluded that the kepok banana stem (Musa acuminata balbisiana Colla) can be used as an adsorbent for $\mathrm{Pb}$ (II) metal ions. Keywords: Adsorption, Heavy metal, metal ion concentration, particle size, Musa acuminata balbisiana Colla
\end{abstract}

(C) 2019 Universitas Abdurrab

Alamat korespondensi: ISSN 2338-4921

Jl. Berok Raya No.29 Jembatan Baru Siteba Padang

E-mail: mega_elfia@yahoo.com 


\section{PENDAHULUAN}

Pertumbuhan penduduk dunia umumnya dan khususnya penduduk Indonesia telah mengakibatkan meningkatnya eksplorasi sumber daya alam untuk memenuhi kebutuhan sandang maupun pangan yang mengakibatkan terjadinya revolusi di bidang pertanian maupun revolusi dibidang industri dimana untuk memproduksi semua kebutuhan manusia setiap industri akan menjalani beberapa tahapan proses mulai dari bahan baku hingga menjadi bahan hasil produksi dari masing -masing industri, dimana setiap tahapan proses sudah dipastiakan ada limbahnya yaitu limbah padat, cair, dan gas [1].

Revolusi pertanian akan menghasilkan limbah padat yang cukup berlimpah di Indonesia, dimana limbah terebut selama ini hanya dibuang, atau dijadikan bahan bakar dan makanan ternak. Limbah hasil pertanian mengandung banyak gugus fungsi senyawa kimia, sehingga dapat digunakan sebagai bahan penyerap untuk limbah cair industri yang mengandung logam berat. Sebagaimana diketahui bahwa logam berat jika berada di badan air akan memberikan dampak negatif yang sangat berbahaya pada kehidupan manusia, hewan maupun organisme lain yang hidup di dalamnya. Oleh karena itu, dirasa sangat perlu untuk mencari dan menyeleksi jenisjenis limbah padat dari pengolahan hasil pertanian yang sangat berpotensi untuk di jadikan sebagai bahan penyerap untuk air limbah industri yang mengandung logam-logam berat [2].

Limbah padat pertanian ini dapat dijadikan sebagai cara alternatif dari beberapa cara yang sudah ada terutama untuk mengurangi biaya produksi yang termasuk dalam biaya pengolahan limbah cair, karena mudah didapat dan biayanya murah, jika di bandingkan dengan menggunakan bahan penyerap karbon aktif, cara elektro deposisi, reverse osmosis, chemical precipitation, maupun resin, yang harganya relatif mahal[3].

Berbagai limbah pertanian telah dilaporkan ternyata dapat menyerap ion-ion logam berat antara lain adalah biji jeruk manis [1], tempurung kelapa [4], alga [2], sabut kelapa [3], daun Akasia [5], kulit pisang dan kulit jeruk [7], kulit delima [8] dan kulit manggis [9]. Batang pisang kepok merupakan limbah pertanian yang sangat jarang sekali dimanfaatkan. Ketersedian bahan baku batang pisang kepok ini sangat mudah didapat. Oleh sebab itu, pemanfaatan batang pisang kapok ini akan dijadikan sebagai biosorben untuk penyerapan zat warna sehingga menjadikan batang pisang kapok ini lebih bermanfaat. Penelitian ini bertujuan untuk mengetahui kapasitas penyerapan dari batang pisang kepok (Musa acuminata balbisiana Colla) terhadap logam $\mathrm{Pb}(\mathrm{II})$.

\section{METODE}

\section{Alat dan Bahan}


Alat-alat yang digunakan dalam penelitian ini adalah Spektofotometer Serapan Atom Raylight WFX-320 BRAIC China, neraca digital KERN 220-4M Germany, pH Universal Merck, blender, kertas saring whatman, dan peralatan gelas lain sesuai prosedur kerja.

Bahan-bahan yang digunakan adalah limbah batang pisang kepok (Musa acuminata balbisiana Colla) diambil di jalan Cipta Karya, Gang Limbat, Pekanbaru, Riau. Reagen yang digunakan untuk penelitian ini adalah $\mathrm{Pb}(\mathrm{NO} 3) 2, \mathrm{HNO} 365 \%$, dan $\mathrm{NaOH}$ yang semuanya mempunyai tingkat kemurnian yang tinggi keluaran E-Merck Darmstad, Germany, etanol destilasi dan akuades.

\section{Pembuatan biosorben batang pisang kepok (Musa acuminata balbisiana Colla)}

Limbah batang pisang kepok (Musa acuminata balbisiana Colla), dibersihkan dari batuan dan tanah yang menempel, kemudian dicuci dengan air bersih dan dijemur di udara terbuka. Setelah kering kemudian dihaluskan dan diayak dengan ayakan berdasarkan ukuran partikel yang akan dipakai $(150 \mu \mathrm{m}, 180 \mu \mathrm{m}, 250 \mu \mathrm{m})$. Limbah batang pisang kepok (Musa acuminata balbisiana Colla) dengan ukuran tersebut direndam dalam larutan HNO3 0,1 M selama 2 jam sambil sesekali diaduk. Hasil rendaman disaring kemudian dicuci dengan akuades. Setelah itu direndam dengan etanol selama 2 jam, kemudian dikeringkan kembali.

Penentuan kondisi optimum limbah batang pisang kepok (Musa acuminata balbisiana Colla)

Pada penelitian ini dilakukan dengan cara dinamis (menggunakan kolom), untuk mengetahui kemampuan penyerapan ion logam timbale oleh batang pisang kepok (Musa acuminata balbisiana Colla). Beberapa variabel yang akan dipelajari adalah ukuran partikel biosorben dan konsentrasi ion logam.

\section{Pengaruh konsentrasi larutan terhadap penyerapan ion logam}

Biosorben ditimbang 1 gram dengan ukuran partikel $150 \mu \mathrm{m}$, kemudian dimasukan kedalam kolom, dan dielusi dengan $20 \mathrm{~mL}$ larutan ion logam konsentrasi yang divariasikan 5, 10, 25, 50, 75, dan $100 \mathrm{mg} / \mathrm{L}$ dengan $\mathrm{pH} 6$ pada kecepatan alir $2 \mathrm{~mL} / \mathrm{menit}$. Filtrat yang dihasilkan dianalisis dengan Spektrofotometer Serapan Atom.

\section{Pengaruh ukuran partikel biosorben}

Biosorben ditimbang 1 gram dengan ukuran partikel 100, 170, dan $200 \mu \mathrm{m}$, kemudian dimasukan ke dalam kolom, dan dielusi dengan $20 \mathrm{~mL}$ larutan ion logam konsentrasi $100 \mathrm{mg} / \mathrm{L}$ dengan kecepatan alir $2 \mathrm{~mL} /$ menit pada $\mathrm{pH}$ 6. Filtrat yang dihasilkan dianalisis dengan Spektrofotometer Serapan Atom.

\section{Analisa Data}


Kapasitas penyarapan ion logam $\mathrm{Pb}$ (II) dihitung berdasarkan persamaan adsorbsi sebagai berikut:

Kapasitas Penyerapan $(m g / g)=\frac{\mathrm{Ce}-\mathrm{Cf}}{m} \times \mathrm{V}$

Efisiensi Penyerapan $(\%)=\frac{\mathrm{Ce}-\mathrm{Cf}}{C e} \times 100 \%$

Keterangan :

$\mathrm{C}_{\mathrm{e}}=$ kosentrasi awal (mg/l)

$\mathrm{C}_{\mathrm{f}}=$ Kosentrasi akhir (mg/l)

$\mathrm{m}=$ massa biosorben $($ gram)

$\mathrm{v} \quad=$ volume larutan $(\mathrm{L})$

$\mathrm{Qe}=$ kesetimbangan konsentrasi ion logam pada sorbent $(\mathrm{mg} / \mathrm{g})$

$\mathrm{Q}_{\max }=$ lapisan monolayer maksimum logam $(\mathrm{mg} / \mathrm{g})$

\section{HASIL DAN PEMBAHASAN}

\section{Pengaruh konsentrasi ion logam terhadap kapasitas penyerapan ion logam $\mathrm{Pb}(\mathrm{II})$}

Pengaruh konsentrasi awal ion logam $\mathrm{Pb}$ (II) dalam larutan dilakukan dengan konsentrasi 5, 10, 25, 50, 75, dan $100 \mathrm{mg} / \mathrm{L}$. Konsentrasi ion logam berhubungan dengan banyaknya ion logam yang dapat berinteraksi dengan sisi aktif material penyerap. Sehingga semakin banyak ion logam dalam larutan maka semakin banyak kemungkinan terjadinya interaksi dengan sisi aktif absorben sehingga kapasitas penyerapannya meningkat. Berikut data kapasitas penyerapan dari batang pisang kepok (Musa acuminata balbisiana Colla) dengan variable konsentrasi ion logam $\mathrm{Pb}(\mathrm{II})$.

Tabel 1. Data Pengaruh Konsentrasi Ion Logam Pb Terhadap Kapasitas Penyerapan Oleh Batang Pisang Kepok (Musa Acuminata Balbisiana Colla)

\begin{tabular}{cccc}
\hline No & $\begin{array}{c}\text { Konsentrasi awal } \\
(\mathrm{Ci})(\mathrm{mg} / \mathrm{L})\end{array}$ & $\begin{array}{c}\text { Konsentrasi akhir } \\
(\mathrm{Cf})(\mathrm{mg} / \mathrm{L})\end{array}$ & $\begin{array}{c}\text { Kapasitas penyerapan } \\
(\mathrm{Q})(\mathrm{g} / \mathrm{mg})\end{array}$ \\
\hline 1 & 5 & 2,184 & 0,0101 \\
2 & 10 & 0,385 & 0,1761 \\
3 & 25 & 1,684 & 0,4678 \\
4 & 50 & 0,519 & 0,9332 \\
5 & 75 & 0,541 & 1,4218 \\
6 & 100 & 0,188 & 1,9510 \\
\hline
\end{tabular}

Pada saat tertentu jumlah sisi aktif akan sama dengan jumlah ion logam,pada saat tersebut penyerapan yang terjadi akan konstan sehingga kapasitas penyerapan akan menurun dengan meningkatnya konsentrasi [10]. Hasil pengukuran pengaruh konsentrasi ion logam yang dianalisa terhadap kapasitas penyerapan batang pisang kepok (Musa acuminata balbisiana Colla) dapat dilihat pada Gambar 1. 


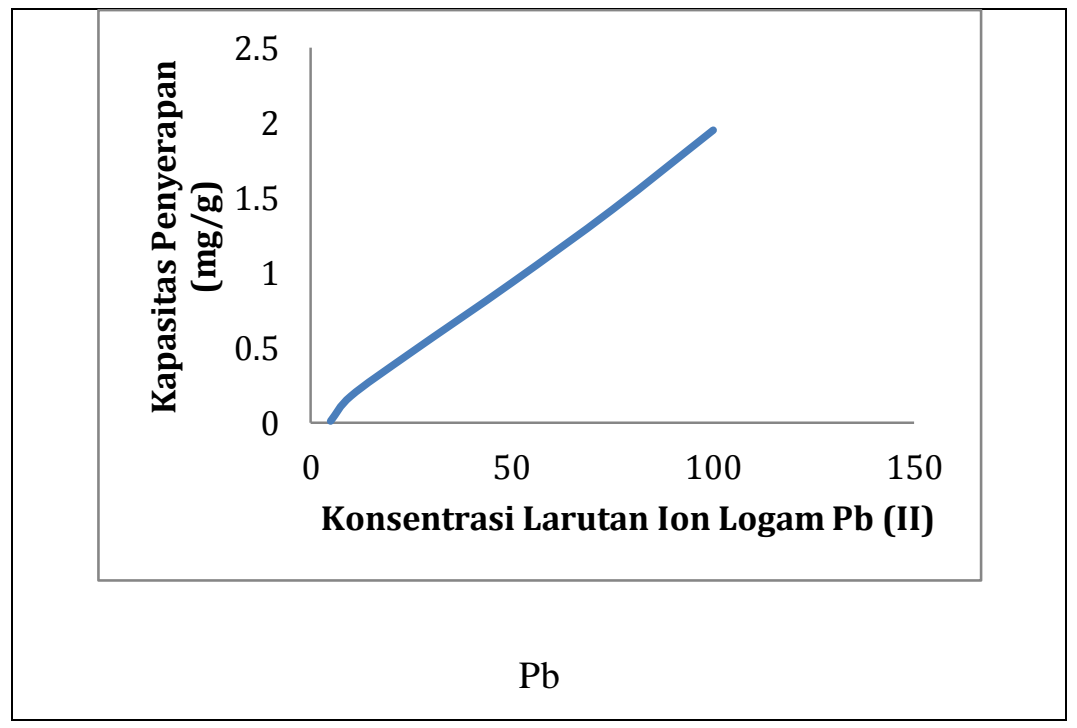

Gambar 1. Pengaruh Konsentrasi Larutan Ion $\mathrm{Pb}$ (II) terhadap kapasitas penyerapan Batang Pisang Kepok (Musa acuminata balbisiana Colla)

\section{Pengaruh Ukuran Partikel Biomaterial terhadap kapasitas penyerapan ion logam $\mathrm{Pb}$ (II)}

Kapasitas penyerapan ion logam $\mathrm{Pb}$ (II) sangat tergantung pada ukuran partikel absorben, dimana hal ini berhubungan dengan luas permukaan. Semakin kecil ukuran partikel, akan semakin besar luas permukaan dan penyerapan akan semakin meningkat. Untuk Hasil Kapasitas penyerapan maksimum ion logam $\mathrm{Pb}$ (II) terjadi pada ukuran partikel $100 \mu \mathrm{m}$ dengan besar kapasitas penyerapan yakni $1.9976 \mathrm{mg} / \mathrm{g}$ dapat dilihat pada Tabel 2.

Tabel 2. Data Pengaruh Partikel Biosorben Batang Pisang Kepok (Musa Acuminata Balbisiana Colla) Terhadap Kapasitas Penyerapan Oleh Ion Logam Pb (II)

\begin{tabular}{cccc}
\hline $\begin{array}{c}\text { Ukuran } \\
\text { Partikel }\end{array}$ & $\begin{array}{c}\text { Konsentrasi awal } \\
(\mathrm{Ci})(\mathrm{mg} / \mathrm{L})\end{array}$ & $\begin{array}{c}\text { Konsentrasi akhir } \\
(\mathrm{Cf})(\mathrm{mg} / \mathrm{L})\end{array}$ & $\begin{array}{c}\text { Kapasitas penyerapan } \\
(\mathrm{Q})(\mathrm{g} / \mathrm{mg})\end{array}$ \\
\hline 100 & 100 & 0.123 & 1.9976 \\
170 & 100 & 0.129 & 1.9974 \\
200 & 100 & 0.124 & 1.9975 \\
\hline
\end{tabular}

Diamati bahwa kapasitas penyerapan meningkat dengan penurunan ukuran partikel biosorben. Peristiwa adsorpsi adalah fenomena permukaan, sehingga tingkat penyerapan berhubungan erat dengan luas permukaan. Oleh karena itu, semakin kecil ukuran partikel, semakin besar penyerapan yang akan terjadi, karena ion-ion akan menembus ke pori-pori dalam partikel [6] [7]. 


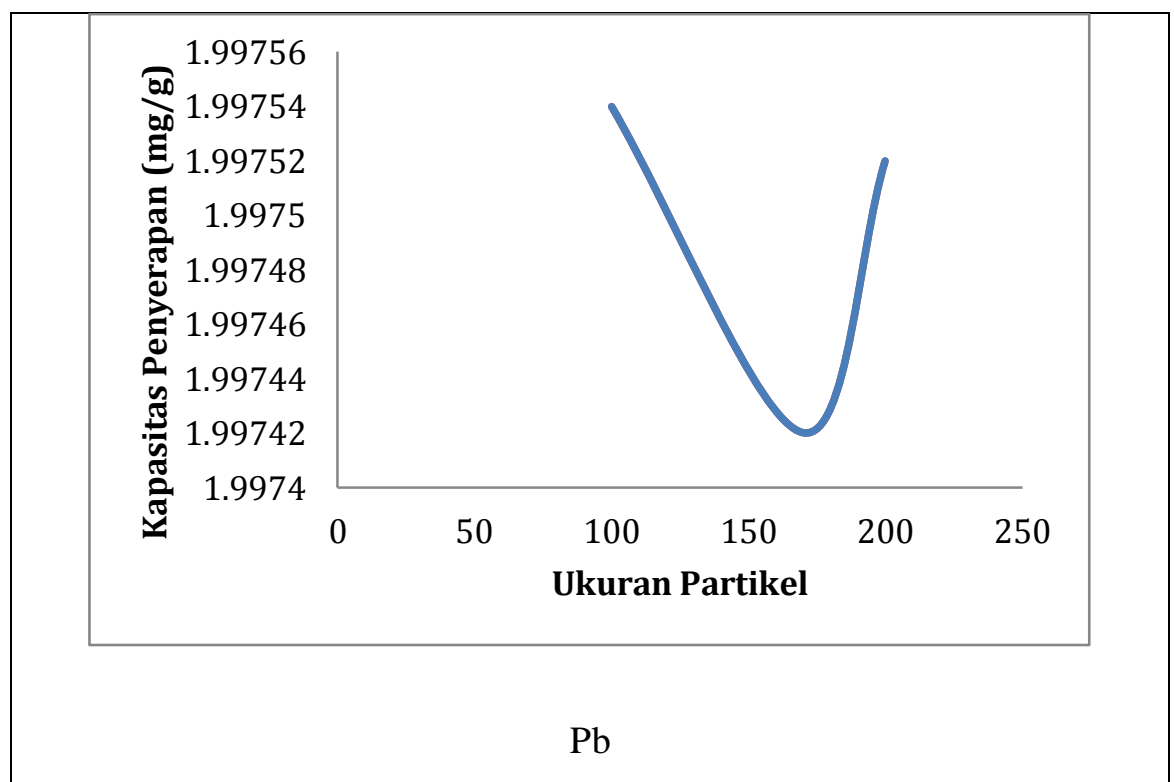

Gambar 2. Pengaruh Ukuran Partikel terhadap kapasitas penyerapan Batang Pisang Kepok (Musa acuminata balbisiana Colla)

\section{SIMPULAN}

Dari hasil penelitian yang telah dilakukan terhadap penyerapan ion logam $\mathrm{Pb}$ (II) menggunakan Batang Pisang Kepok (Musa acuminata balbisiana Colla), dapat diambil kesimpulan bahwa: Batang Pisang Kepok (Musa acuminata balbisiana Colla) dapat digunakan sebagai bahan penyerap ion logam $\mathrm{Pb}$ (II). Untuk penyerapan optimum terjadi pada konsentrasi larutan ion logam $100 \mathrm{mg} / \mathrm{L}$ dan ukuran partikel $100 \mu \mathrm{m}$. Pada kondisi optimum tersebut diperoleh kapasitas penyerapan Batang Pisang Kepok (Musa acuminata balbisiana Colla) terhadap ion logam $\mathrm{Pb}$ (II) adalah $1,9976 \mathrm{mg} / \mathrm{g}$.

\section{UCAPAN TERIMA KASIH}

Penulis mengucapkan terima kasih kepada pihak DRPM Ditjen Penguatan Risbang, Kementrian Riset, Teknologi, Dan Pendidikan Tinggi. yang telah memberikan dana untuk riset ini

\section{DAFTAR PUSTAKA}

1. Jimoh, T.O, J. Yisa, A.I. Ajai, and A. Musa. 2013. Kinetic and Thermodynamics Studies of the Biosorption of $\mathrm{Pb}$ (II), Cd (II) and $\mathrm{Zn}$ (II) ion from Aqueous Solution by Sweet orange (Citrua sinensis) Seed. Internasional Journal of Modern Chemistry. 4(1): 19-37 
2. Jafari N., Z. Senobari. 2012. Removal of $\mathrm{Pb}$ (II) ion from aqueous solution by Cladophora rivularis (Linnaeus) hoek. The Scientific World Journal, vol. 2012.

3. De Lima, A.C.A., Nascimento, R.F., de Sousa, F.F., Filho, J.M. and Oliveira, A.C. (2012). Modified coconut shell fibers: A green and economical sorbent for the removal anions from aqueous solutions. Chemical Engi-neering, 274-284. Faiza Mureed, Razuya Nadeem, Ansar Mehmood. 2012. Biosorption of Zinc by Chemically Modified Biomass of Corncob (Zea mays .L). Middle-East Journal of Scientific Research, 11 (9): 1226-1231

4. Asiagwu, A.K, Hilary I. Owamah and O. Christoper. 2013. Kinetik Model for the Sorption of $\mathrm{Ni}(\mathrm{II}), \mathrm{Cu}(\mathrm{II})$ and $\mathrm{Zn}$ (II) onto Cocos Mucifera Fiber Biomass from Aqueous Solution. $J$ Chem Eng Process Technol . 4:2

5. Magan Lal, Sumit, Shobha Sharma and Vikal Gupta. 2013. Removal of Cr(III) by activated Acacia Nilotica Leaf Powder. Eur. Chem. Bull. 2 (3), 144-148

6. Baral, S.S., Dasa, S.N. Chaudhury G.R., Swamya, Y.V and Rath P. 2007. Removal of Cr(VI) by thermally acticated weed Salvinia cucullata in a fixed-bed colomn, Journal of Hazardous Materials 161:1427-1435.

7. Kamsonlian. S, S. Suresh, C.B. Majumder and S. Chand. 2011. CHARACTERIZATION OF BANANA AND ORANGE PEELS: BIOSORPTION MECHANISM. International Journal of Science Technology \& Management

8. Moghadam R.M, Navid, N. Zienab, D. Esmaeil, B. 2013. Removal of Fe(II) from Aqueous solution using pomegranate peel carbon: equilibrium and kinetic studies. Internasional Journal of Industrial Chemistry, 4:9

9. Zein. R., Suhaili. R, Earnestly. F, Indrawati, Munaf. E, 2010. Removal of Pb(II), Cd(II), and $\operatorname{Co}($ II) from aqueos solution using Garcinia mangostana L fruit shell. Journal of Hazardous Materials. $181: 52-56$

10. Munaf. E and R. Zein, The use of rice husk for removal of toxic metals from wastewater, Environ. Technol., 18, (359-362) 1997 